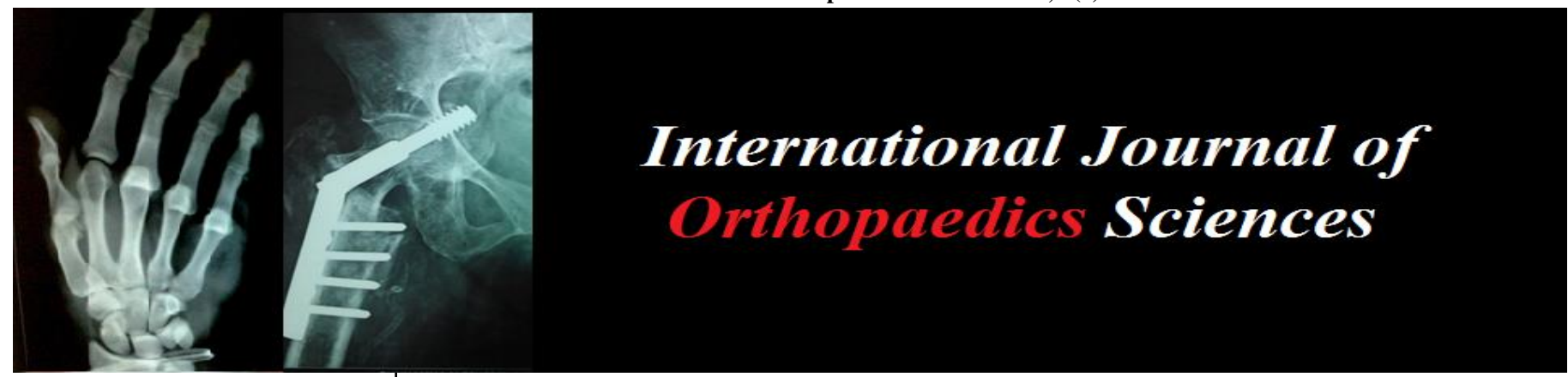

E-ISSN: 2395-1958

P-ISSN: 2706-6630

IJOS 2019; 5(4): 1027-1031

(C) 2019 IJOS

www.orthopaper.com

Received: 13-08-2019

Accepted: 17-09-2019

Dr. Venkat Rama Choudary

Pathuri

Assistant Professor, Department of Orthopaedics, GSL Medical

College Rajahmundry, Andhra Pradesh, India
Corresponding Author:

Dr. Venkat Rama Choudary

Pathuri

Assistant Professor, Department of Orthopaedics, GSL Medical College Rajahmundry, Andhra Pradesh, India

\section{A prospective comparative evaluation of proximal femoral nailing and dynamic hip screw in treatment of intertrochanteric fracture in tertiary care hospital}

\author{
Dr. Venkat Rama Choudary Pathuri
}

DOI: https://doi.org/10.22271/ortho.2019.v5.14r.1815

Abstract

Back ground: Intertrochanteric fractures are extra capsular fractures of the proximal femur that occurs between greater and lesser trochanter. This fracture comprises of half of the all hip fracture which occurs due to low energy mechanism, and is likely to increase. Intramedullary nailing is used to treat a broader range of intertrochantric fracture, it is less invasive, blood loss is less, and allow early weight bearing. But there are very few data suggesting that intramedullary nailing hip screw is more of effective than dynamic hip screw.

Material and method: A sample size of 60 was selected for this study using purposive sampling technique. All patients were evaluated as history and mode of injury, radiological evaluation of fracture, and haematological profile was done. For pre injury walking ability evaluation Sahlstrand classification was used. X- ray AP and lateral view of hip was taken. Bohler - Braun frame was used to put skin traction. General condition of all patients was evaluated and corrective measure was taken. Fracture was classified based on Jensen and michealsen's modification of Evans classification.

Result: Regarding intra operative variables as per table-2, the mean duration of surgery in group A was $63.23+9.27$ min in group B it was $87.866+4.15 \mathrm{~min}$, The $\mathrm{P}$ value was 0.0001 The mean amount of blood loss $136 \pm 40.46 \mathrm{ml}$ in group $\mathrm{A}$ and $385 \pm 74.42 \mathrm{ml}$ in group B. The P value was 0.0001 . In group A mean of length of incision was $9.4 \pm 1.246 \mathrm{~mm}$ and in group B it was $14.48 \pm 0.94 \mathrm{~cm}$. The $\mathrm{P}$ value was 0.0001 .

Discussion and conclusion: Based on our observation we can conclude that intra operative profile is better in proximal femoral nailing then dynamic hip screw. The blood loss was less, duration of surgery was less and the size of incision was less in proximal femoral nailing. Proximal femoral nailing has better out come in terms of early mobilisation of patient.

Keywords: Intertrochanteric fracture, proximal femoral nailing, dynamic hip screw, comparison

\section{Introduction}

With the availability of quality health care life expectancy of individual has increased. So the frequency of fracture of geriatric group has also become common. Intertrochanteric fractures are extra capsular fractures of the proximal femur that occurs between greater and lesser trochanter. This fracture comprises of half of the all hip fracture which occurs due to low energy mechanism, and is likely to increase ${ }^{[1,2]}$. This fracture occurs in both young and old age, but it is more common in old age, female, osteoporosis and history of low energy fall, but is unusual in young ${ }^{[3]}$. As these parts of bone are spongy or trabecular bone with good blood supply so, nonoperative management can be one option but outcome of this method is poor as it is associated with risk of immobilisation like decubitus ulcer, DVT, aspiration pneumonia, and embolism

So operative management of these fracture is considered, with an aim to restoration of the patients functional status as early as possible and to reduce morbidity and mortality. But surgical management also have challenges, that is instability and complication due to instability, stability of the internally fixed fracture is its ability to resist muscle pull and force of gravitation on the hip that try to force the fracture into virus position. Factors which is responsible for the failure of the internal fixation is method of reduction, selection of implant, size of implant, techniques used, osteoporosis and comminution of the fracture. Most of the fracture is treated either by dynamic hip screw or intramedullary hip screw. 
Dynamic hip screw is used for stable fracture with intact lateral wall if used properly it allow dynamic inter fragmentary compression and cost is low, but the disadvantage is there is more blood loss as it is an open technique and implant failure. Intramedullary nailing is used to treat a broader range of intertrochantric fracture, it is less invasive, blood loss is less, and allow early weight bearing ${ }^{[2]}$. But there are very few data suggesting that intramedullary nailing hip screw is more of effective than dynamic hip screw $[4,5]$.

Keep this in view present study has been designed to verify the advantages of intramedullary device like proximal femoral nailing over the dynamic hip screw device in intertrochantric fracture patient.

\section{Objective}

Primary object: To compare, the duration of surgery, blood loss, fracture union and post-operative infection.

Secondary objective: Functional outcome of the treatment we start with the hypothesis that proximal femoral nailing is a superior treatment for intertrochantric fracture as compared to dynamic hip screw.

\section{Material and method}

Present study is a prospective, comparative study conducted in the department of orthopaedics GSL medical college Rajamundry Andhra Pradesh from July 2017 to September 2019.

Selection of patient: All patients with fresh intertrochantric fracture based on exclusion and inclusion criteria were included in this study.

\section{Inclusion}

Age $>18 \mathrm{yrs}$

Both sex

Fresh fracture,

Mobile before fracture

\section{Exclusion \\ Pre existing import \\ Deformity of female \\ Pathological frame \\ Old complicated fracture.}

\section{Ethics}

This study is approved by institutional ethics committee. A written informed consent was obtained from all patients before enrolment for this study.

\section{Sample size}

A sample size of 60 was selected for this study using purposive sampling technique ${ }^{[6]}$. They were divided into two group, Group A includes 30 patients have undergone proximal femoral nailing, Group B includes 30 patients undergone dynamic hip screw fixation.

\section{Method}

All patients were evaluated as history and mode of injury, radiological evaluation of fracture, and haematological profile was done. For pre injury walking ability evaluation Sahlstrand classification was used ${ }^{[7]}$. X- ray AP and lateral view of hip was taken. Bohler - Braun frame was used to put skin traction. General condition of all patients was evaluated and corrective measure was taken. Fracture was classified based on Jensen and michealsen's modification of Evans classification ${ }^{[8]}$. All patients was given same prophylactic medication. If procedure was prolonged amino glycosides were added in addition to useful antibiotic.

\section{Procedure}

All patients were positioned supine on a fracture table, and fracture was reduced by closed method.

\section{Proximal femoral nailing}

The diameter of nail was determined by measuring the diameter of the femur, at the level of isthmus using an anterioposterior X- ray. Neck shaft angle was measured on opposite side, by using goniometer and standard size proximal femoral nail was used in all cases.

\section{Dynamic hip screw}

The length of compression screw was measured from tip of the head to the base of greater trochanter, neck shaft angle was determined by same way. Length of side plate was at least 8 cortices to the shaft distal to the fractures. All cases were operated under local anaesthesia using standard operating teaching of the implant used. In the post-operative period patients were allowed to sit in bed on 2nd post OP, static quadriceps exercise, 3rd day, and suture were removed from $11^{\text {th }} 14^{\text {th }}$ day. All patients were followed for 6 weeks, 3 months and 6months, check X-ray was taken, walking ability was compared with pre injury walking. Pain was evaluated by using four point pain score. Varus angulations more that $10^{0}$ were considered malunion. Functional outcome was measured as post-operative pain, walking ability, hip joint range of motion and limb length shortening.

If patient has no pain in post-operative period, range of motion $80 \%$, able to walk without support and shortening was $0.5 \mathrm{~cm}$ the outcome was considered excellent.

If there was mild pain, shortening 0.5 to $1.5 \mathrm{~cm}$, range $60 \%$ to $80 \%$ and able to walk with support then it was good. Similarly patient was moderate pain, hip range 40 to $60 \%$ shortening $1.5 \%$ to $2.5 \%$ and able to work with support then outcome was fair. Anything less than that was poor.

\section{Result}

Present study involved 60 patients' selected based on inclusion and exclusion criteria, out of 60 patients thirty patients were treated with proximal femoral nail and 30 patients were treated with dynamic hip screw.

Table 1: Demography of the patients in pre op

\begin{tabular}{|c|c|c|c|c|}
\hline \multirow{2}{*}{\multicolumn{2}{|c|}{$\begin{array}{c}\text { variables } \\
\text { Age (Yrs) (mean + SD) } \\
\end{array}$}} & \multicolumn{2}{|c|}{ Type of fixation } & \multirow{4}{*}{\begin{tabular}{|c|} 
P value \\
0.15358 \\
$\begin{array}{c}0.6053 \text { (with Yates correction) } \\
\text { chi -square statistic }(0.026)\end{array}$ \\
\end{tabular}} \\
\hline & & Group A(PFN) 61.4+11.72 & Group B(DHS) 58.32+11.223 & \\
\hline \multirow{2}{*}{$\operatorname{sex}$} & $\mathrm{M}$ & 16 & 13 & \\
\hline & $\mathrm{F}$ & 14 & 17 & \\
\hline \multirow{3}{*}{ Made of injury } & Trivial fail & $20(66.67 \%)$ & $18(60 \%)$ & \multirow{3}{*}{$\begin{array}{c}0.8535 \text { square statistic } \\
=0.2933\end{array}$} \\
\hline & Accident & $6(20 \%)$ & $7(23.34 \%)$ & \\
\hline & Fail from weight & $4(13.34 \%)$ & $5(16.67 \%)$ & \\
\hline \multirow{2}{*}{ Side of injury } & $\mathrm{Rt}$ & $10(33.3 \%)$ & $16(53.34 \%)$ & \multirow{2}{*}{0.118017} \\
\hline & Left & $20(66.67 \%)$ & $14(46.67 \%)$ & \\
\hline Type of & Type-I & $4(13.34)$ & $2(6.67 \%)$ & 0.685571 chi-square statistic \\
\hline
\end{tabular}




\begin{tabular}{|c|c|c|c|c|}
\hline \multirow{3}{*}{ fracture } & Type-II & $14(46.67 \%)$ & $16(53.34 \%)$ & \multirow{2}{*}{1.4857} \\
\cline { 2 - 4 } & Type-III & $8(26.67 \%)$ & $6(20 \%)$ & \\
\cline { 2 - 4 } & Type-IV & $4(13.34 \%)$ & $6(20 \%)$ & $2686.67 \%)$ \\
\multirow{2}{*}{ Walking ability } & grade-I & $24(80 \%)$ & $4(13.34 \%)$ & 0.488244 chi-square state 0.48 \\
\cline { 2 - 4 } & grade-II & $6(20 \%)$ & & \\
\hline
\end{tabular}

It has been observed as per table 1 that mean age of the patient was 61.4 \pm 11.72 yrs in group $A(P F N)$ and $58.32 \pm 11.223$ yrs in group $B$. The $P$ value was 0.15 . The minimum age was $33 \mathrm{yrs}$ and maximum age was $81 \mathrm{yrs}$. There was 31 female and 29 male in total, in group A there were 16 male and 14 female, but in group B there were 13 male and 17 female the $\mathrm{P}$ value was 0.6053. In Group A 20 out of 30patients has trivial fall, that is $(66.67 \%)$. But in Group B (DHS) $18(60 \%)$ patients have trivial fall. Out of 30 patients in group A, 6 have accident that is $20 \%$ and in group B accident was mode of injury in 7 patients. In group A fall from height was mode of injury in 4 patients, in group $B$ it was in 7 patients. In group A 20 patients have left side injury and 10 patient have right side injury. In group B 16 patients have right side injury and 14 patients haves left side injury. There was no significant difference between two groups. Regarding type of fracture, type- 1 fracture was present in 4 patients in group A and 2 pts in group B. Type II fracture was present in 14 patients in group A and 16 patients in group B. Type III fracture was present in 8 patients in group A an 6 patients in group B. Type IV fracture was present in 4 patients in group A and two patients in group B. There was no significant difference between two group regarding type of fracture. Group A having walking ability grade 1 in 24 patients and grade II in 6 patients, Group B having walking ability grade 1 in 26 patients and grade II in 4 patients. The $P$ value was 0.488 .

Table 2: Intra operative variables of patients

\begin{tabular}{|c|c|c|c|}
\hline \multirow{2}{*}{ variables } & \multicolumn{2}{|c|}{ groups } & \multirow{2}{*}{ P value } \\
\cline { 2 - 3 } & Group A(PFN) & Group B(DHS) & \\
\hline Duration of surgery (min) Mean \pm SD) & $63.23 \pm 9.77$ & $87.86 \pm 4.15$ & $0.0001 \mathrm{~T}=12.4923$ \\
\hline Blood loss $(\mathrm{ml})$ Mean \pm SD) & $136 \pm 40.46$ & $385 \pm 74.42$ & 0.0001 \\
\hline Length of incision(cm) Mean $\underline{+S D}$ & $9.4 \pm 1.246$ & $14.18 \pm 0.94$ & 0.0001 \\
\hline
\end{tabular}

Regarding intra operative variables as per table-2, the mean duration of surgery in group A was $63.23 \pm 9.27 \mathrm{~min}$ in group $\mathrm{B}$ it was $87.866+4.15 \mathrm{~min}$, The $\mathrm{P}$ value was 0.0001 The mean amount of blood loss $136 \pm 40.46 \mathrm{ml}$ in group $\mathrm{A}$ and $385 \pm 74.42 \mathrm{ml}$ in group B. The $\mathrm{P}$ value was 0.0001 . In group $\mathrm{A}$ mean of length of incision was $9.4 \pm 1.246 \mathrm{~mm}$ and in group B it was $14.48 \pm 0.94 \mathrm{~cm}$. The $\mathrm{P}$ value was 0.0001 .

Table 3: post-operative variables.

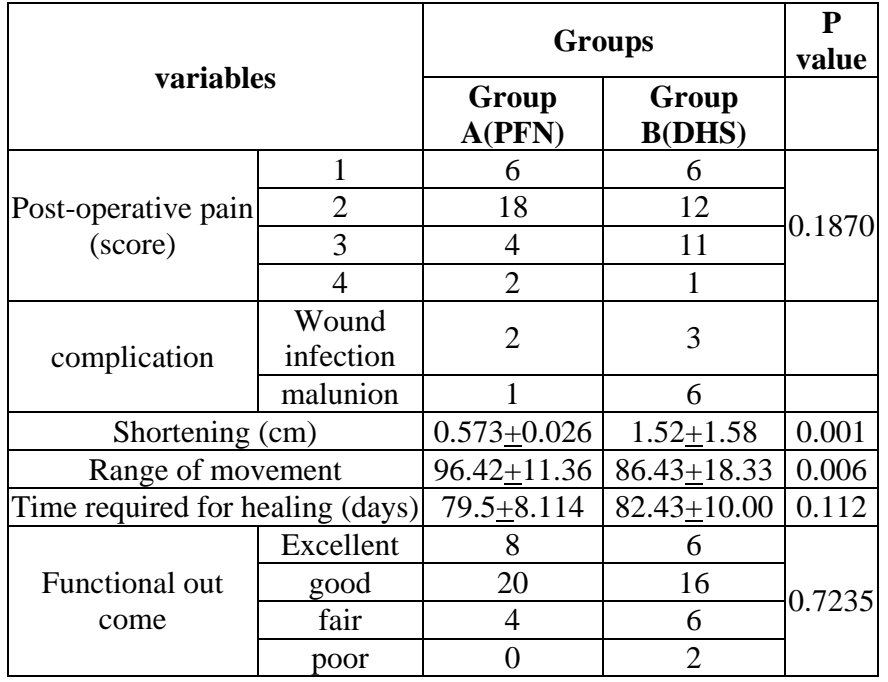

As per table-3, regarding post-operative variables postoperative pain score was 1 in 6 patient in group $A$ and 6 patients in group B. In group A pain score was 2 in 18 patients and in group B it was 2 in 12 patients, pain score was 3 in four patients in group A and eleven patients in group B. The pain score was 4 in two patients in group $A$ and 3 patients in group $\mathrm{B}$. The $\mathrm{P}$ value was 0.18 which in not significant. Regarding complication of surgery in group A 2 patients have developed wound infection and 1 patient have malunion. In group B 3 patients developed wound infection and 6 patient having malunion.

The mean of shortening of length in group $\mathrm{A}$ was $0.573 \pm 0.026 \mathrm{~cm}$ and group $\mathrm{B}$ it was $1.52 \pm 1.57 \mathrm{~cm}$. The $\mathrm{P}$ value was 0.0001 , which is significant. The time required for healing in group A was $79.5+8.1114$ and in group B it was $82.43+10.00$ days

The $\mathrm{P}$ value was 0.112 . The functional outcome was excellent in 8 patients in group A and 6 patients in group B. It was good in 20 patients in group $A$ and 16 patients in group B, fair in 4 patients in group A and 6 patients in group B. Two patients in group $\mathrm{B}$ have poor result. The $\mathrm{P}$ value was 0.7235 which is not significant.

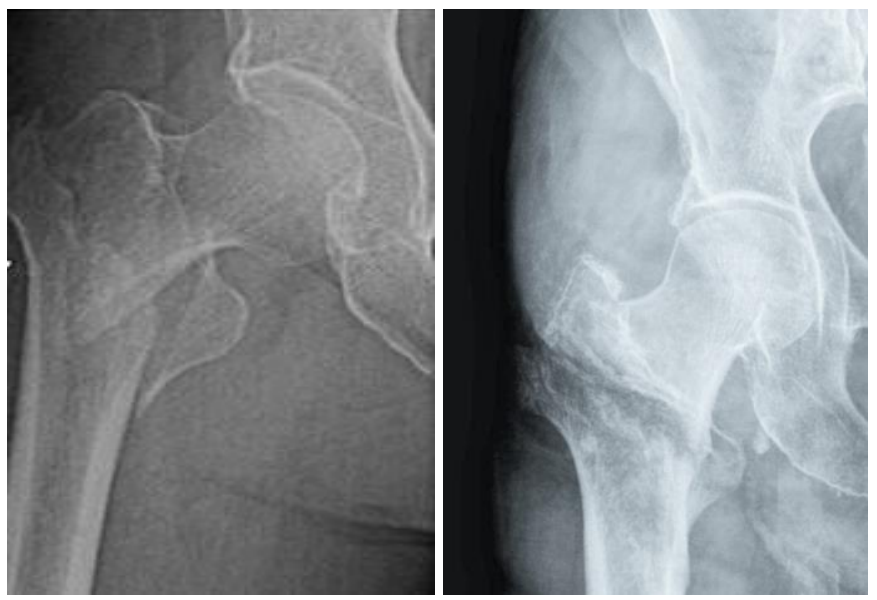

Fig 1: Intertrochantric fracture 


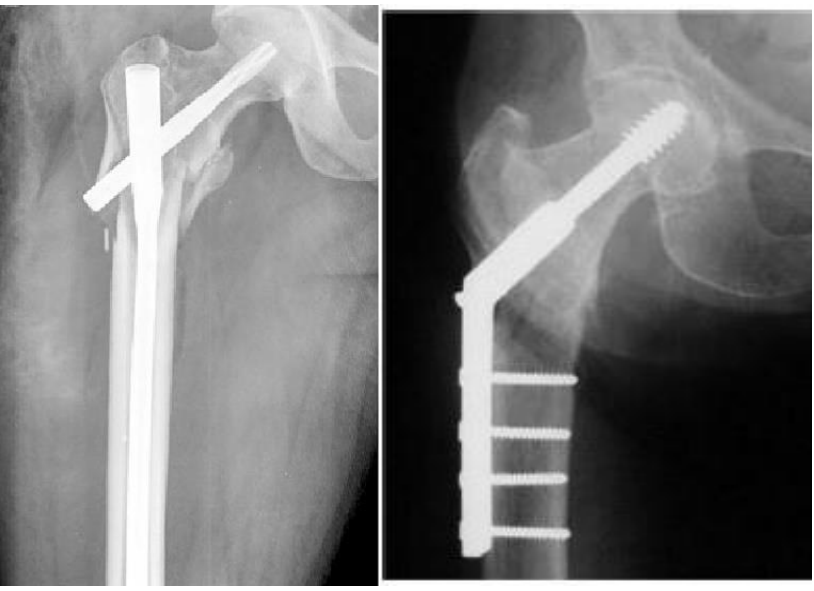

Fig 2: proximal femoral nailing and dynamic hip screw

\section{Discussion}

Present study has been conducted on 60 patients with an aim to compare the functional outcome intertrochantric fracture treated with two different fixation methods.

In present study the mean of age of patients with fracture was comparable to each other in both group and it was $61.7 \pm 11.72$ yrs in group A and 58.22 \pm 11.223 yrs in group B. Out of 60 patients 31 patients were female and 29 were male. This finding is supported by the work of Kumar $\mathrm{R}$ et al. and Endigeri et al. ${ }^{[9,10]}$.

Trivial fall was common in both group followed by accident, and left side fracture was common than right side in both group this finding corroborates with the finding of Melton L.S et al. ${ }^{[11]}$ In present study type II fracture is most common followed by it is type III. But Lan $\mathrm{H}$ et al. has reported that type III is more common then type II. ${ }^{[12]}$ Shukla et al. has reported that type III and type IV are more common ${ }^{[13]}$ So there is variability regarding type of fracture in various studies. Regarding walking abilities most of the patients have grade I difficulties which is supported by the work of Ran Tao et al. ${ }^{[14]}$.

Regarding intra operative variables of the patients, the duration surgery was significantly less in group A then group B $(62.23 \pm 9.77 \mathrm{~min}$ vs $87.876 \pm 4.15 \mathrm{~min})$. This finding is supported by the work of Saudan et al. and the meta analysis of Zhansk et al. ${ }^{[15,16]}$ Blood loss and length of incision was also significantly less in group A than group B, which corroborates with work of Pajarinen $\mathrm{J}$ et al. and Pan X-h et al. [17, 18]. Post-operative pain score was less in group A than group B but was not significant statistically. This finding is supported by the work of Zhangk et al. ${ }^{[16]}$. Post-operative infection was in 2 patients out of 30 in group $A$ and 3 patients one of 30 in group B. Malunion was also less in group A than group B. This finding is supported by the work of Shen-H-M et al. and Zhaoc et al. ${ }^{[19,20]}$.

Shortening was significantly less in group A than group B which corroborates with the finding of Kumar R et al. ${ }^{[9]}$. Post operative range of hip movement was significantly better in group A than group B, this find is similar to the finding of Soudan $\mathrm{M}$ et al. ${ }^{[15]}$.

Time required for healing was less and functional outcome was better in group A but it is not significant statistically. This observation corroborates with the observation of Pajarinen and Shan-H-m et al. ${ }^{[17,19]}$.

\section{Conclusion}

Based on our observation we can conclude that intra operative profile is better in proximal femoral nailing then dynamic hip screw. The blood loss was less, duration of surgery was less and the size of incision was less in proximal femoral nailing. Proximal femoral nailing has better out come in terms of early mobilisation of patient.

\section{Reference}

1. Jaimo Ahn MD, Joseph Bernstein MD. Intertrochanteric Hip Fractures, Clin Orthop Relat Res. 2010; 468:14501452

2. Attum B, Pilson H. Intertrochanteric Femur Fracture. [Updated 2019 Jun 15]. In: Stat Pearls [Internet]. Treasure Island (FL): Stat Pearls Publishing, 2019. Jan. Available https://www.ncbi.nlm.nih.gov/books/NBK493161/

3. Grisso JA, Kelsey JL, Strom BL, Chiu GY, Maislin G, O'Brien LA et al. Risk factors for falls as a cause of hip fracture in women. The Northeast Hip Fracture Study Group. N Engl J Med. 1991; 324:1326-1331.

4. Tucker A, Donnelly KJ, Rowan C, McDonald S, Foster AP. Is the Best Plate a Nail? A Review of 3230 Unstable Intertrochanteric Fractures of the Proximal Femur. J Orthop Trauma. 2018; 32(2):53-60.

5. Sharma A, Sethi A, Sharma S. Treatment of stable intertrochanteric fractures of the femur with proximal femoral nail versus dynamic hip screw: A comparative study. Rev Bras Ortop. 2018; 53(4):477-481.

6. Jacqueline M, Guarte, Erniel B. Barrios. Estimation Under Purposive Sampling, Communications in Statistics - Simulation and Computation. 2006; 35(2):277-284. DOI: 10.1080/03610910600591610)

7. Sahlstrand T. The Richards compression and sliding hip screw system in the treatment of intertrochanteric fractures. Acta Urthop. Scand. 1974; 45:213-219.

8. Evans EM. The treatment of trochanteric fractures of the femur. J Bone Jt Surg. 1949; 31-B:190-203.

9. Kumar R, Singh RN, Singh BN. Comparative prospective study of proximal femoral nail and dynamic hip screw in treatment of intertrochanteric fracture femur. J Clin Orthop Trauma. 2012; 3(1):28-36. Doi: 10.1016/j.jcot.2011.12.001

10. Endigeri P, Pattanashetty OB, Banapatti DB, Pillai A, Ullas T. Outcome of intertrochanteric fractures treated with proximal femoral nail: A prospective study. J Orthop Traumatol Rehabil [serial online] [cited 2019 Nov 29]. 2015; 8:25-9. Available from: http://www.jotr.in/text.asp?2015/8/1/25/183951

11. Melton LJ, Kearns AE, Atkinson EJ. Secular trends in hip fracture incidence and recurrence. Osteoporos Int. 2009; 20(5):687-694.

12. Lan H. Treatment of different types of intertrochanteric fractures in the elderly with internal fixation, Zhongguo Gu Shang. 2008; 21(7):532-3

13. Shukla R, Sharma D, Jain RK. Trochanteric fixation nail in inter trochanteric fractures of femur in adult population. Afr. J Trauma [serial online] [cited 2019 Nov 30]. 2017; 6:27-31. Available from: http://www.afrjtrauma.com/text.asp?2017/6/2/27/2 45260

14. Ran Tao, Yue Lu, Hua Xu, Zhen Yu Zhou, You-Hua Wang, Fan Liu. Internal Fixation of Intertrochanteric Hip Fractures: A Clinical Comparison of Two Implant Designs, The Scientific World Journal, Article ID 834825, 2013, 7. https://doi.org/10.1155/2013/834825.

15. Saudan M, Lübbeke A, Sadowski C et al. Pertrochanteric fractures: is there an advantage to an intramedullary 
nail?: a randomized, prospective study of 206 patients comparing the dynamic hip screw and proximal femoral nail. J Orthop Trauma. 2002; 16:386-93.

16. Zhang K, Zhang S, Yang J et al. Proximal femoral nail vs. dynamic hip screw in treatment of intertrochanteric fractures: a meta-analysis. Med Sci Monit. 2014; 20:1628-1633. Published $2014 \quad$ Sep 12. doi:10.12659/MSM.890962

17. Pajarinen J, Lindahl J, Michelsson $\mathrm{O}$ et al. Pertrochanteric femoral fractures treated with a dynamic hip screw or a proximal femoral nail: a randomised study comparing postoperative rehabilitation. J Bone Joint Surg Br. 2005; 87:76-81.

18. Pan XH, Xiao DM, Lin BW. Dynamic hip screws (DHS) and proximal femoral nails (PFN) in treatment of intertrochanteric fractures of femur in elderly patients. Chin J Orthop Trauma. 2004; 7:785-89.

19. Shen HM, Liang CW, Fan YQ. The Clinical Study of the Treatment of Intertrochanteric Fractures in the Elderly with DHS, Gamma nail and PFN. Chinese Journal of Clinical Medicine. 2007; 2:226-28.

20. Zhao C, Liu DY, Guo JJ. Comparison of proximal femoral nail and dynamic hip screw for treating intertrochanteric fractures. China J Orthop \& Trauma. 2009; 7:535-37. 